\title{
Statistical modeling and optimal energy distribution of cogeneration units by genetic algorithms
}

\author{
Othmane Maakoul ${ }^{1}$, Hamid El Omari ${ }^{1}$, Aziza Abid ${ }^{2}$ \\ ${ }^{1}$ Laboratory of Renewable Energies Environment and Development, Faculty of Science and Technology, Hassan $1^{\text {st }}$ University, \\ Settat City, Morocco \\ ${ }^{2}$ Laboratory LaSTI, National School of Applied Sciences, Sultan Moulay Slimane University, Beni Mellal City, Morocco
}

\begin{tabular}{l}
\hline Article Info \\
\hline Article history: \\
Received Mar 1, 2021 \\
Revised Oct 29, 2021 \\
Accepted Nov 14, 2021 \\
\hline
\end{tabular}

Keywords:

Cogeneration unit

Cost of operation

Gas emissions

Genetic algorithms

Optimization

Statistical model

\begin{abstract}
Our main objective is to evaluate the performance of a new method to optimize the energy management of a production system composed of six cogeneration units using artificial intelligence. The optimization criterion is economic and environmental in order to minimize the total fuel cost, as well as the reduction of polluting gas emissions such as COx, NOx and SOx. First, a statistical model has been developed to determine the power that the cogeneration units can provide. Then, an economic model of operation was developed: fuel consumption and pollutant gas emissions as a function of the power produced. Finally, we studied the energy optimization of the system using genetic algorithms (GA), and contribute to the research on improving the efficiency of the studied power system. The GA has a better optimization performance, it can easily choose satisfactory solutions according to the optimization objectives, and compensate for these defects using its own characteristics. These characteristics make GA have outstanding advantages in iterative optimization. The robustness of the proposed algorithm is validated by testing six cogeneration units, and the obtained simulation results of the proposed system prove the value and effectiveness of GA for efficiency improvement as well as operating cost minimization.
\end{abstract}

This is an open access article under the CC BY-SA license.

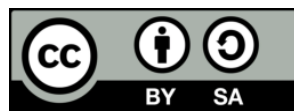

\section{Corresponding Author:}

Othmane Maakoul

Laboratory of Renewable Energies Environment and Development, Faculty of Science and Technology,

Hassan $1^{\text {st }}$ University

Settat City, Morocco

Email: othmane.1992.mkl@gmail.com

\section{INTRODUCTION}

The global demand for energy has increased strongly in the last decades due to the industrial revolution and the change of lifestyle. On the one hand, the reserves of fossil resources (oil, natural gas, coal) are limited, and on the other hand, the use of these resources is responsible for the increase of greenhouse gas (GHG) concentrations in the atmosphere, leading to global warming [1]. Among the solutions adopted to ensure an energy transition to non-polluting and reliable energies, we find the cogeneration units that help to approve the demand for electricity and heat during peak periods with a total efficiency that exceeds $80 \%$ [2], [3], which will significantly reduce the electricity purchase bill following a decrease in the amount of electricity purchased from the supplier. It is a technology that can work with several types of fuel and is independent of climatic conditions [4], [5], unlike other renewable energies that are intermittent, such as solar and wind power [6].

Optimization of power generation sources is becoming a critical necessity in order to increase the efficiency of the generation system while minimizing losses and emissions of pollutants [7]. An optimized 
generation system is one that allows for a shift from a demand-driven generation system to one based on electricity supply, feed-in tariffs and electrical energy storage [8]-[10].

This work is structured by two parts: the first part proposes a statistical modeling of a cogeneration system, which allows the determination of the net heat requirement, determination of the thermal and electrical power according to different criteria: combination of a minimum cost of the system for a requested power in order to better meet the requirements, while taking into account the place where they are installed and the construction costs according to a worst case mission profile. The second part is dedicated to the adaptation of an intelligent optimization strategy to manage the energy distribution of the different cogenerators installed in an electrical grid, which must satisfy the needs of consumers while respecting the various constraints related to the operation of the production sources (maximum power, total efficiency, energy losses) [11].

There are several optimization methods of energy systems applied for the objectives of minimizing the operating cost and the emissions of pollutants [12]-[14], but these methods may have some limitations when solving an objective function and may not be applicable to some complex functions. A new solving method has been developed that can overcome these limitations and is more robust, called genetic algorithm (GA) optimization, it is a powerful method with strong adaptation in artificial systems, flexible, wellbalanced mechanism and is suitable for solving a single objective optimization problem (production cost optimization, optimization gas emissions) in which the power grid is fed by the cogeneration plant.

\section{RESEARCH METHOD}

\subsection{Studied energy production grid}

The objective of the expected statistical model is to have a tool to help the dimensioning and the evaluation of the efficiency of a cogeneration unit from an energetic, environmental and economic point of view. This model should ideally be able to predict the behavior of any type of cogenerator, and be easily parameterized, depending on the optimization algorithms developed. The Figure 1 shows the structure of the energy production system constituted by cogenerations fed by different types of fuel.

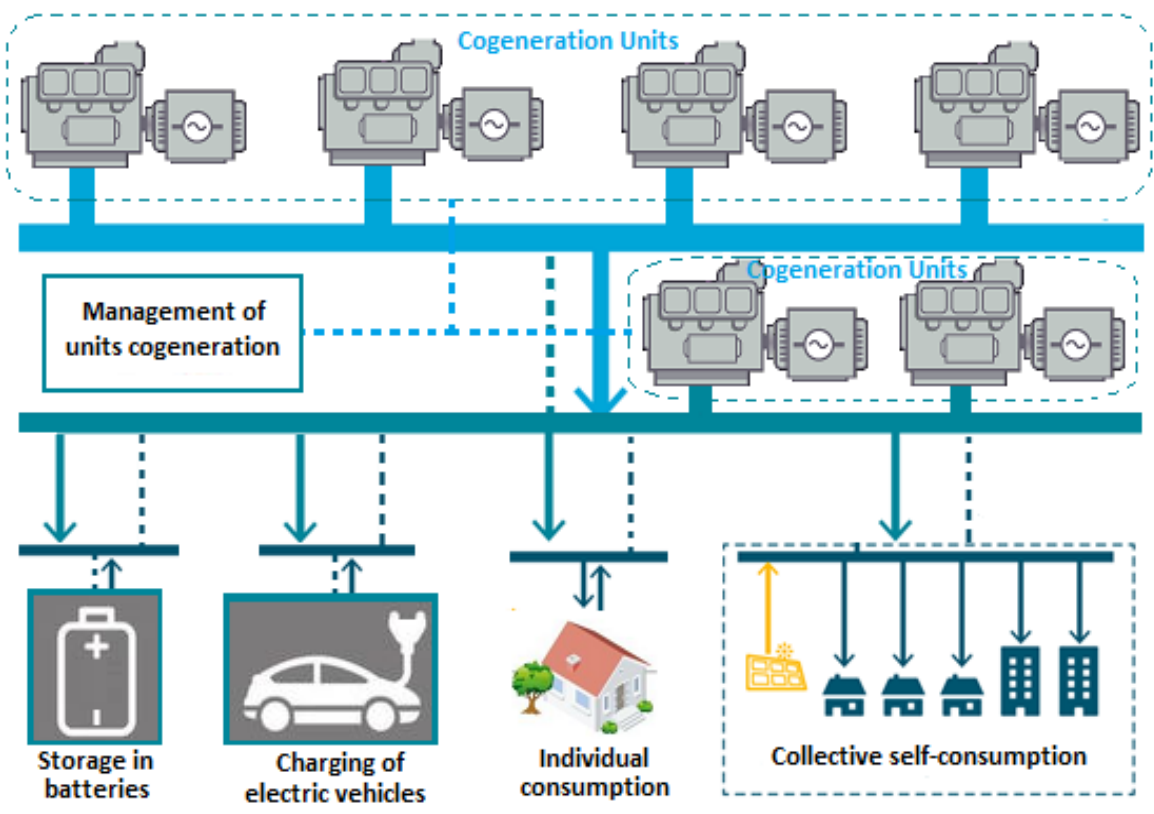

Figure 1. Overview diagram of the production system

\subsection{Statistical model of a cogeneration group}

A statistical model is based on field measurements (daily, monthly, and annual energy consumption profile). These models are empirical and do not require a precise knowledge of the system components or their interactions [15]. For a cogeneration unit this model takes as input the probability densities of fuel supply (fuel) and power demanded by the consumer load. They provide probabilities of fuel savings and other data useful for economic-financial evaluations (maintenance costs, price per $\mathrm{KWh}$ produced, 
contribution to $\mathrm{CO}_{2}$ emission). Noting that these models are difficult to transport from one site to another and do not allow for specificities such as energy storage or energy flows through the system to be taken into account [16].

\subsubsection{Determination of the net heat requirement}

In the majority of cases, to obtain a cogeneration that makes the most of the energy produced, the unit is sized according to the heat requirements, as the electricity produced can always be either consumed internally or sold to the grid via a device for synchronization to the electrical grid [17]. At this stage, the net heat requirement $(\mathrm{BNeC})$ must be deducted, which is expressed by (1):

$$
\mathrm{BNeC}=\eta_{\text {boiler room }}(\mathrm{Q}-\text { Losses })(\text { Kwh/year })
$$

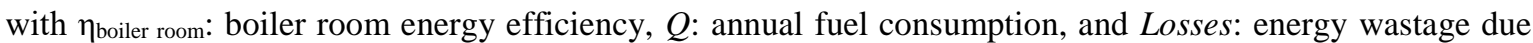
to poor insulation or poor regulation.

\subsubsection{Determination of the electrical power of the cogeneration unit}

Each "typical profile" of heat consumption corresponds to an optimal size to meet this essential constraint "valorizing all the heat produced". The energy profiles can be influenced by different parameters: seasonality, geographical location, consumer behavior, technical restrictions [11], [17]. This optimal size is

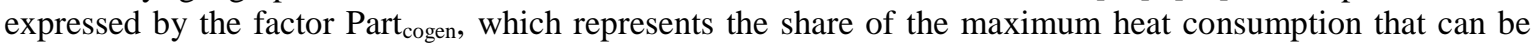
provided by the cogeneration unit. The thermal capacity of the cogeneration unit:

$$
P_{Q \operatorname{cogen}}=\frac{B N e C \cdot \text { Part }_{\text {cogen }}}{U_{Q}}\left(\mathrm{KW}_{\mathrm{q}}\right)
$$

where $U_{Q}$ : the number of hours that a properly sized conventional heating system should operate at rated capacity to produce the net heat demand.

The amount of heat supplied by the cogeneration unit is:

$$
Q_{\text {cogen }}=P_{Q \operatorname{cogen}} \cdot U_{\text {cogen }}\left(\mathrm{KWh}_{\mathrm{q}}\right)
$$

the two parameters of the pre-dimensioning, $U_{\text {cogen }}$ and $P a r t_{\text {cogen }}$, are thus known, with the $U_{\text {cogen }}$ is the base of the rectangle, represents the operating time of the cogeneration unit at full power. The annual quantity of electricity produced by the cogeneration becomes:

$$
E_{\text {cogen }}=P_{\text {Ecogen }} \cdot U_{\text {cogen }}\left(\mathrm{KWh}_{\mathrm{e}}\right)
$$

\subsection{Optimization of the energy distribution of the studied grid}

In the literature a number of methods for the optimization of energy flows [18]-[20]. For all methods it is necessary to have a consumption profile during a reference period in order to make a calculation of energy balance at all levels of the system. The energy produced by the grid must adjust in real time to the consumption of users, depending on the power capacities, characteristics and potentials of the technologies used [21], [22]. The optimization problem of our case study "the objective function" is the constrained minimization of the total discounted operating cost and the minimization of the toxic gas emissions.

\subsubsection{Problem statement and constraints}

- Cogeneration system (CHP): The electrical energy produced by the cogenerator set noted $\mathrm{P}_{\mathrm{CHP}}(\mathrm{t})$ will be used to meet the demand and $\eta_{e-C H P}$ is the electrical efficiency of the conversion of the fuel into usable electricity, and $\mathrm{P}_{\mathrm{CHP}}(\mathrm{t})$ is the total energy produced including electricity, heat and losses.

$$
\mathrm{P}_{\mathrm{CHP}}(\mathrm{t})=\eta_{\mathrm{e}-\mathrm{CHP}} \cdot \mathrm{P}_{\mathrm{CHP}^{\prime}}(\mathrm{t})
$$

- Supply/demand energy flow balance: The energy production system is designed to supply a complete electrical load noted $P_{c}(t)$, with $P_{c^{\prime}}(t)$ the total electrical power supplied by the studied grid. At each time interval $t$ the balance is expressed as in (6):

$$
\sum \mathrm{P}(\mathrm{t})=0 \quad ; \mathrm{P}_{\mathrm{c}^{\prime}}(\mathrm{t})-\mathrm{P}_{\mathrm{c}}(\mathrm{t})=0
$$


- Type profiles of an electrical load: In our case, we have adopted the data of electrical energy consumption of a collective building, considered has a surface of $500 \mathrm{~m}^{2}$ during a day (24 hours) of basic test, with a step of one hour. Figure 2 shows the daily curve of electricity demand during the winter season.

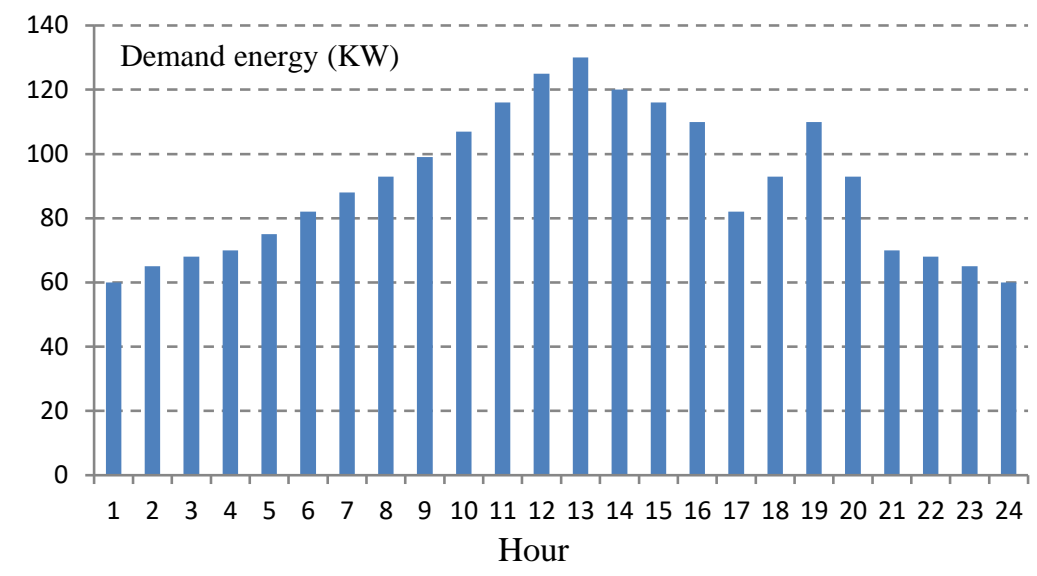

Figure 2. Demand energy data in KW

\subsubsection{Optimization of the fuel cost function}

The operating cost for each cogeneration unit for the different fuels used is usually modeled by an objective function in second degree polynomial form in power output [23].

$$
C_{\text {total }}=\sum_{i=1}^{6}\left(C_{i}\right)=\sum_{i=1}^{6}\left(\alpha_{i}+\beta_{i} \cdot P_{i}+\gamma_{i} \cdot P_{i}^{2}\right) \quad[\$ / h]
$$

Where $\alpha_{i}, \beta_{i}, \gamma_{i}$ are constant coefficients specific to cogenerator $i$.

To solve the problem of economic optimization of the production of electrical energy, i.e. to minimize the total cost of the fuel necessary for this production, which is presented in the form of a nonlinear function, taking into account certain constraints of type equality and inequality. For the six cogeneration groups, the power output $\left(\mathrm{P}_{\mathrm{CHPi}}\right)$ is bounded by an upper limit $\left(\mathrm{P}_{\mathrm{CHPi}-\mathrm{max}}\right)$ and a lower limit $\left(\mathrm{P}_{\mathrm{CHPi}-\mathrm{min}}\right)$, which gives the inequality (9):

$$
\begin{aligned}
& \min C_{\text {total }}=\min \sum_{i=1}^{6}\left(\alpha_{i}+\beta_{i} \cdot P_{i}+\gamma_{i} \cdot P_{i}^{2}\right)[\$ / h] \\
& p_{C H P-\min } \leq p_{C H P-i} \leq p_{C H P-\max }
\end{aligned}
$$

with $\mathrm{i}=1,2, \ldots 6$.

\subsubsection{Optimization of the toxic gas emission function}

In the first case study, we dealt with the problem of optimizing the emission function of toxic gases to the environment, on a first test grid of 6 production units. This first case is devoted to the analysis of the problem of the emission of toxic gases based on quadratic emission functions for the gases (NOx, COx, SOx) treated individually and non-linear type for the case treated together, the technical characteristics of the production units are presented in Table 1. For this problem, the formulation is the same as the fuel cost but one needs to replace the cost coefficients with emission coefficients.

$$
E_{\text {total }}=\sum_{i=1}^{4}\left(E_{i}\right)=\sum_{i=1}^{4}\left(A_{i}+B_{i} \cdot P_{i}+C_{i} \cdot P_{i}^{2}\right)
$$


Table 1. Specifications for the $\mathrm{CHP}_{\mathrm{S}}$ units

\begin{tabular}{ccccccccccccc}
\hline & \multicolumn{3}{c}{ Fuel cost } & \multicolumn{4}{c}{ NOx emission parameters } & \multicolumn{3}{c}{ Cox emission parameters } & \multicolumn{3}{c}{ Sox emission parameters } \\
$\mathrm{CHP} \mathrm{N}$ & $\alpha_{\mathrm{i}}$ & $\beta \mathrm{i}$ & $\gamma_{\mathrm{i}}$ & $\mathrm{A}_{\mathrm{i}}$ & $\mathrm{Bi}$ & $\mathrm{C}_{\mathrm{i}}$ & $\mathrm{A}_{\mathrm{i}}$ & $\mathrm{Bi}$ & $\mathrm{C}_{\mathrm{i}}$ & $\mathrm{A}_{\mathrm{i}}$ & $\mathrm{Bi}$ & $\mathrm{C}_{\mathrm{i}}$ \\
\hline $\mathrm{CHP}_{1}$ & 200 & 7.95 & 0.0016 & 81 & -0.39 & 0.0064 & 5000 & -62 & 0.27 & 52 & 6 & 0.0013 \\
$\mathrm{CHP}_{2}$ & 190 & 7.82 & 0.0025 & 30 & -0.81 & 0.0065 & 3900 & -30 & 0.15 & 185 & 4 & 0.0025 \\
$\mathrm{CHP}_{3}$ & 150 & 7.97 & 0.0031 & 300 & -1.42 & 0.0032 & 1350 & -10 & 0.11 & 510 & 5 & 0.0015 \\
$\mathrm{CHP}_{4}$ & 170 & 7.75 & 0.048 & 550 & -2.41 & 0.0070 & 1900 & -13 & 0.11 & 170 & 6 & 0.0082 \\
$\mathrm{CHP}_{5}$ & 180 & 7.85 & 0.040 & 320 & -1.35 & 0.0032 & 1350 & -10 & 0.12 & 515 & 5 & 0.0014 \\
$\mathrm{CHP}_{6}$ & 100 & 7.92 & 0.050 & 50 & -0.38 & 0.0062 & 1200 & -120 & 0.40 & 125 & 5 & 0.0041 \\
\hline
\end{tabular}

\subsection{Optimization by a genetic algorithm}

When solving an objective function by traditional optimization methods one can be limited to local maxima (or minima), so these methods are not applicable to some complex functions. To solve these problems a new optimization method has been developed that can overcome these limitations; called population-based genetic algorithms find near-optimal solutions to difficult optimization problems [24], [25]. Genetic algorithm (GA) is an optimization technique based on the principle of natural selection for reproduction and for various other operations such as crossover and mutation [26]. Genetic algorithms aim to define an approximate solution to an optimization problem in a reasonable time, when there is no exact method to solve it or the duration of the computational phase is too long on the human life scale [27].

In order to optimize a problem with an unknown solution, a set of possible solutions is randomly generated. This composition is called "the population" [28]. The variables in a GA are then used in gene sequences that will be combined with other genes to form chromosomes, and then individuals [29]. Each solution is represented by an individual; this individual is evaluated and then classified according to its similarity to the best solution to the problem. As in biological systems, the best individuals in the population are those that have a better chance of reproducing and giving some of their genes to the next generation. A new population (generation) will be created by arranging the genes of the parents [30]. Some individuals in the new generation have the best characteristics of both parents, so they will be better and present a better solution to the problem.

\section{RESULTS AND DISCUSSION}

In order to evaluate the performance of the algorithmic optimization method, we adopted a test system with 6 cogeneration units powered by different fuel types. The objective functions of our system (operating cost, toxic gas emission) of each cogeneration unit are chosen as a quadratic function. The proposed method for optimization by an AG was implemented in MATLAB. The code represented by the binary format is 16 bits long for each generator. The distribution of the energies of the CHPs: in this case, we applied our optimization program to a mono-objective minimization of the objective functions: operating cost and gas emissions.

Figure 3 shows the optimal energy distribution of the six CHP units to meet a specified demand. This distribution corresponds to the lowest possible operating cost of the system. At this point the simulation results obtained under ToolBox/MATLAB concerning the minimization of the cost function are optimal values respecting the equality/inequality constraints of the powers generated by the six CHPs. Figures 4-6 give an acceptable result of the minimization of emission functions as a function of the power generated by the cogeneration units.

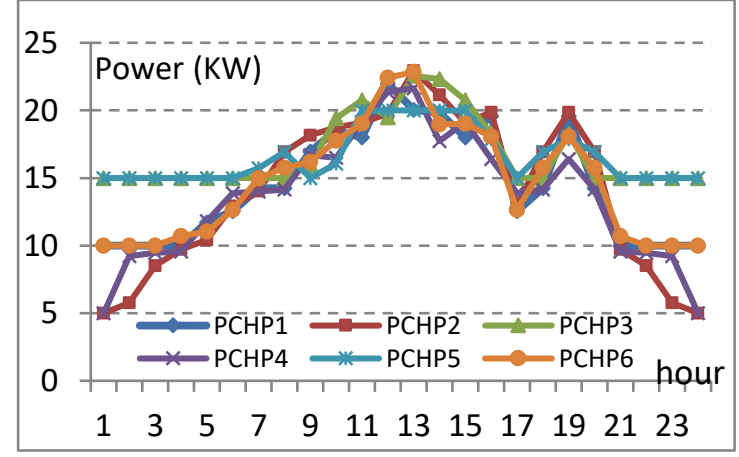

Figure 3. Repartition with minimization of the operating cost

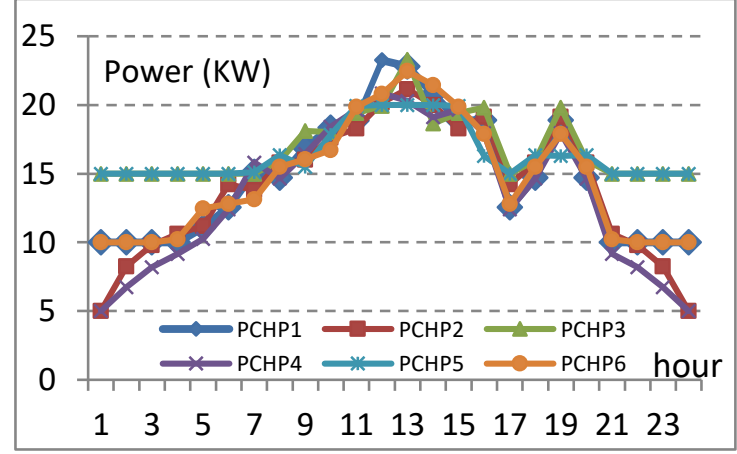

Figure 4. Repartition with minimization of NOx 


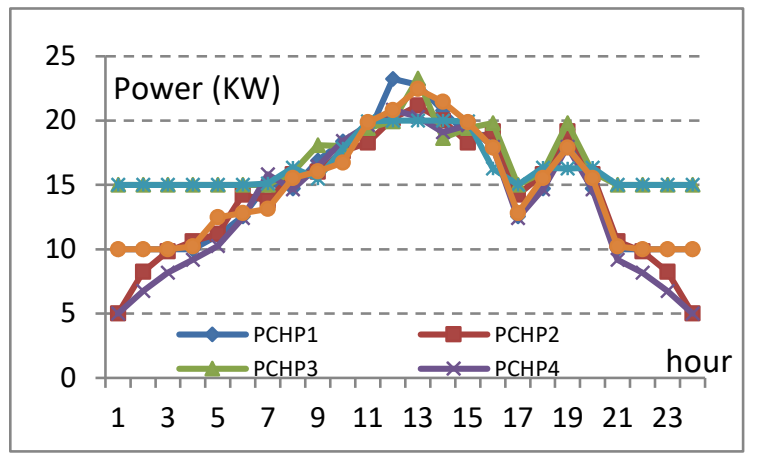

Figure 5. Repartition with minimization of COx emissions

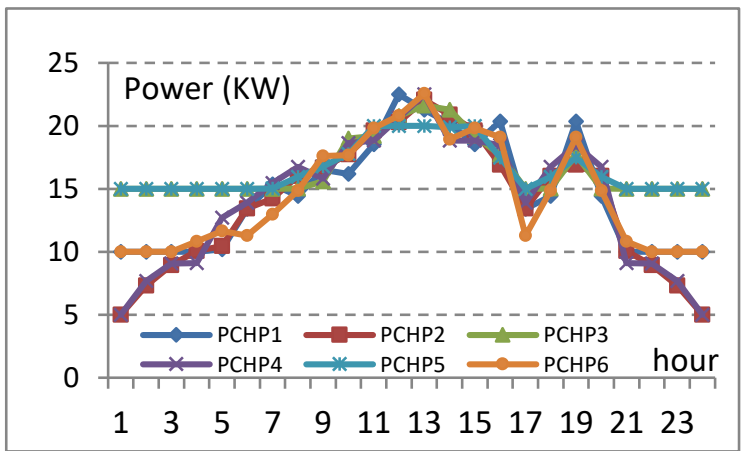

Figure 6. Repartition with minimization of SOx emissions

The graph in Figure 7 gives the final value of the optimal operating cost optimized for a power demand of $130 \mathrm{KW}$ is obtained equal to 990 dollars (minimum in this case). And the 2nd one at the bottom shows the number of the best individuals corresponding to each variable of the function. For NOx, COx and SOx emissions are shown in Figures 8, Figure 9, and Figure 10, the optimal values obtained are 1331, 14700, $1557(\mathrm{Kg} / \mathrm{h})$ respectively, which are acceptable results of the minimization of the emission functions.

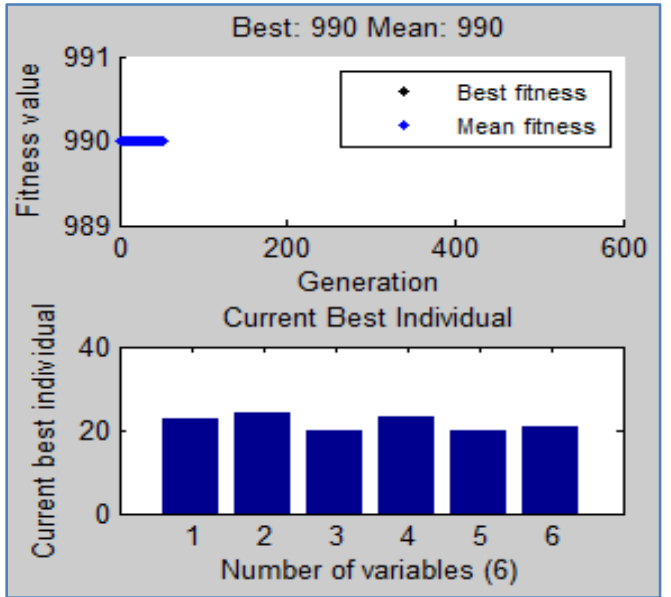

Figure 7. Cost function optimization

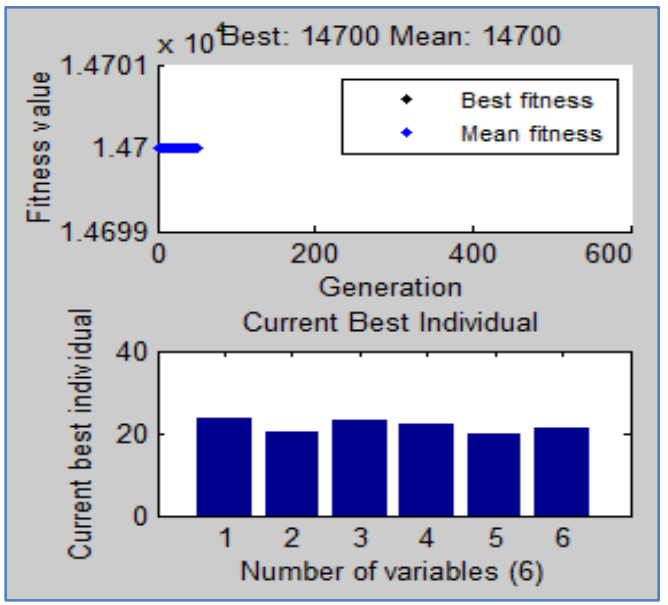

Figure 9. COx emission optimization

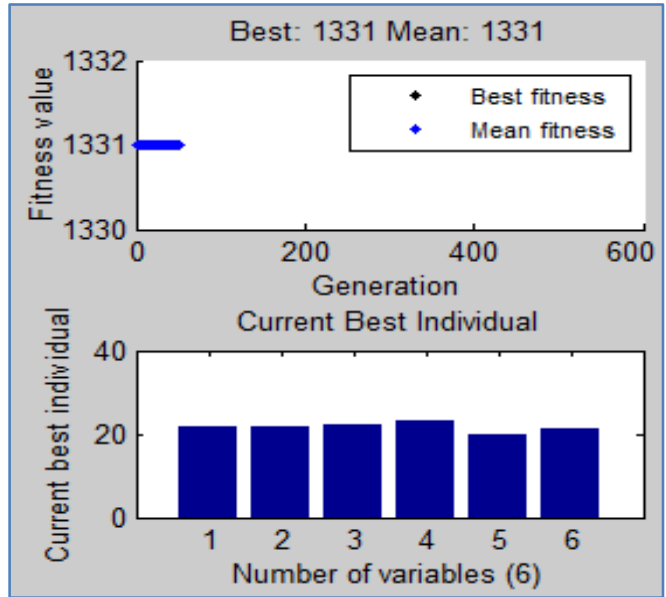

Figure 8. NOx emission optimization

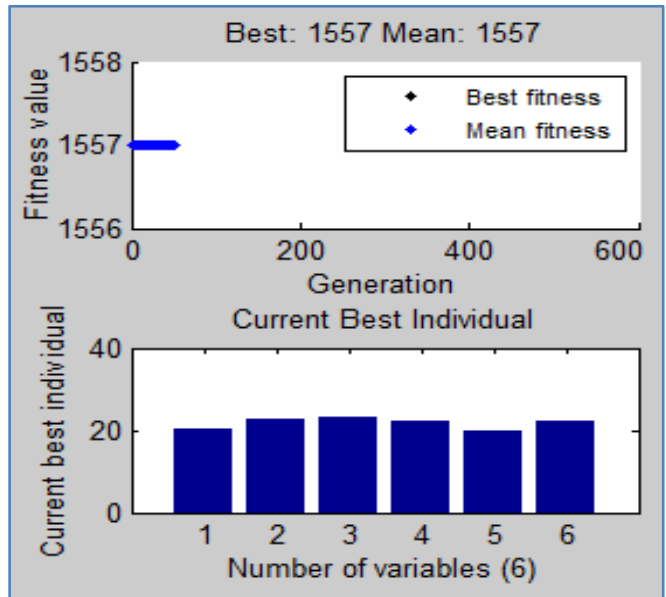

Figure 10. SOx emission optimization 


\section{CONCLUSION}

The present work is a contribution to the optimization of the energy distribution of an electrical network constituted by cogeneration groups by applying a new meta-heuristic algorithm, called genetic algorithm, whose objective functions is to minimize the total cost of operation of the system as well as the toxic gas emissions. The results obtained by simulation show economically acceptable performances, with a strict respect of the technical conditions at the active power produced.

In the continuation of this research work, it is necessary to improve the studied power generation system either from the point of view of modeling the cogeneration units and from the point of view of optimization by using genetic algorithms. These improvements must also take into account the load losses in the CHPs. In order for the algorithm to be fully self-adaptive, it is essential to incorporate an economic model to account for fuel costs, energy sold into the power grid, and maintenance costs. In this way, it might not even be simply static, as is currently the case, but evolve with research progress.

\section{ACKNOWLEDGEMENTS}

The research team would like to thank the National Center for Scientific and Technical Research, for its funding of the project "Study of appropriate technologies for the conversion of organic waste and biomass into renewable energy and sustainable bio-fertilization".

\section{REFERENCES}

[1] S. Baral and G. Xydis, "How green energy giants increase their revenues? Impacts on global warming," in Climate Change Science, Elsevier, 2021, pp. 247-271.

[2] Y. S. Mohammed, M. W. Mustafa, and N. Bashir, "Hybrid renewable energy systems for off-grid electric power: Review of substantial issues," Renewable and Sustainable Energy Reviews, vol. 35, pp. 527-539, Jul. 2014, doi: 10.1016/j.rser.2014.04.022.

[3] F. Legrottaglie, E. Mattarelli, C. A. Rinaldini, and F. Scrignoli, "Application to micro-cogeneration of an innovative dual fuel compression ignition engine running on biogas," International Journal of Thermofluids, vol. 10, May 2021, Art. no. 100093, doi: 10.1016/j.ijft.2021.100093.

[4] M. Dumas, J. Rising, and J. Urpelainen, "Political competition and renewable energy transitions over long time horizons: A dynamic approach," Ecological Economics, vol. 124, pp. 175-184, Apr. 2016, doi: 10.1016/j.ecolecon.2016.01.019.

[5] G. Vialetto and M. Noro, "An innovative approach to design cogeneration systems based on big data analysis and use of clustering methods," Energy Conversion and Management, vol. 214, Jun. 2020, Art. no. 112901, doi: 10.1016/j.enconman.2020.112901.

[6] Y. Cao et al., "Seasonal design and multi-objective optimization of a novel biogas-fueled cogeneration application," International Journal of Hydrogen Energy, vol. 46, no. 42, pp. 21822-21843, Jun. 2021, doi: 10.1016/j.ijhydene.2021.04.044.

[7] M. F. Roslan, M. A. Hannan, P. Jern Ker, R. A. Begum, T. M. Indra Mahlia, and Z. Y. Dong, "Scheduling controller for microgrids energy management system using optimization algorithm in achieving cost saving and emission reduction," Applied Energy, vol. 292, Jun. 2021, Art. no. 116883, doi: 10.1016/j.apenergy.2021.116883.

[8] S. C. Swain, S. Panda, A. K. Mohanty, and C. Ardil, "Application of computational intelligence techniques for economic load dispatch," World Academy of Science, Engineering and Technology, vol. 39, pp. 781-789, 2009, doi: 10.5281/zenodo.1056689.

[9] H. K. Alfares and M. Nazeeruddin, "Electric load forecasting: Literature survey and classification of methods," International Journal of Systems Science, vol. 33, no. 1, pp. 23-34, Jan. 2002, doi: 10.1080/00207720110067421.

[10] L. dos S. Coelho and C. S. Lee, "Solving economic load dispatch problems in power systems using chaotic and Gaussian particle swarm optimization approaches," International Journal of Electrical Power and Energy Systems, vol. 30, no. 5, pp. 297-307, Jun. 2008, doi: 10.1016/j.ijepes.2007.08.001

[11] G. Zhang, Y. Cao, Y. Cao, D. Li, and L. Wang, “Optimal energy management for microgrids with combined heat and power (CHP) generation, energy storages, and renewable energy sources," Energies, vol. 10, no. 9, Aug. 2017, Art. no. 1288, doi: 10.3390/en10091288

[12] J. B. Park, K. S. Lee, J. R. Shin, and K. Y. Lee, “A particle swarm optimization for economic dispatch with nonsmooth cost functions," IEEE Transactions on Power Systems, vol. 20, no. 1, pp. 34-42, Feb. 2005, doi: 10.1109/TPWRS.2004.831275.

[13] H. Altun and T. Yalcinoz, "Implementing soft computing techniques to solve economic dispatch problem in power systems," Expert Systems with Applications, vol. 35, no. 4, pp. 1668-1678, Nov. 2008, doi: 10.1016/j.eswa.2007.08.066.

[14] J. H. Holland, "Adaptation in Natural and Artificial Systems," in Adaptation in Natural and Artificial Systems, Ann Arbor: University of Michigan Press, 2019.

[15] R. Maamri, "Modeling and experimentation of combustion engines running on different alternative fuels and blends," Trois Rivières University in Quebec, 2014.

[16] T. Daho et al., "Influence of engine load and fuel droplet size on performance of a CI engine fueled with cottonseed oil and its blends with diesel fuel," Applied Energy, vol. 111, pp. 1046-1053, Nov. 2013, doi: 10.1016/j.apenergy.2013.05.059.

[17] A. Pirmohamadi, M. Ghazi, and M. Nikian, "Optimal design of cogeneration systems in total site using exergy approach," Energy, vol. 166, pp. 1291-1302, Jan. 2019, doi: 10.1016/j.energy.2018.10.167.

[18] B. Mahdad, T. Bouktir, and K. Srairi, "Optimal power flow of the Algerian network using Genetic Algorithm/Fuzzy rules," Jul. 2008, doi: 10.1109/PES.2008.4596656

[19] K. Senthil and K. Manikandan, "Improved tabu search algorithm to economic emission dispatch with transmission line constraint," Search, vol. 1, no. 2, pp. 145-149, 2010

[20] D. E. Goldberg, "Genetic algorithm," in search, optimization and machine learning, Indiana: Addison-Wesley Professional, 1989.

[21] R. Baños, F. Manzano-Agugliaro, F. G. Montoya, C. Gil, A. Alcayde, and J. Gómez, "Optimization methods applied to renewable and sustainable energy: A review," Renewable and Sustainable Energy Reviews, vol. 15, no. 4, pp. 1753-1766, May 2011, doi: 10.1016/j.rser.2010.12.008.

[22] A. L. Devi and O. V. Krishna, "Combined economic and emission dispatch using evolutionary algorithms-A case study," Journal of Engineering and Applied Sciences, vol. 3, no. 6, pp. 28-35, 2008. 
[23] K. P. Wong and Y. W. Wong, "Genetic and genetic/simulated-annealing approaches to economic dispatch," IEE Proceedings: Generation, Transmission and Distribution, vol. 141, no. 5, pp. 507-513, 1994, doi: 10.1049/ip-gtd:19941354.

[24] K. H. K. Reddy, A. K. Luhach, B. Pradhan, J. K. Dash, and D. S. Roy, "A genetic algorithm for energy efficient fog layer resource management in context-aware smart cities," Sustainable Cities and Society, vol. 63, Dec. 2020, p. 102428, doi: 10.1016/j.scs.2020.102428.

[25] R. Derollepot and E. Vinot, "Sizing of a combined series-parallel hybrid architecture for river ship application using genetic algorithm and optimal energy management," Mathematics and Computers in Simulation, vol. 158, pp. 248-263, Apr. 2019, doi: 10.1016/j.matcom.2018.09.012.

[26] B. Grosch, T. Kohne, and M. Weigold, "Multi-objective hybrid genetic algorithm for energy adaptive production scheduling in job shops," Procedia CIRP, vol. 98, pp. 294-299, 2021, doi: 10.1016/j.procir.2021.01.106.

[27] A. G. Bakirtzis, P. N. Biskas, C. E. Zoumas, and V. Petridis, "Optimal power flow by enhanced genetic algorithm," IEEE Transactions on Power Systems, vol. 17, no. 2, pp. 229-236, May 2002, doi: 10.1109/TPWRS.2002.1007886.

[28] M. Younes, M. Rahli, and L. A. Koridak, "Economic power dispatch using evolutionary algorithm," Journal of Electrical Engineering, vol. 57, no. 4, pp. 211-217, 2006

[29] I. G. Damousis, A. G. Bakirtzis, and P. S. Dokopoulos, "Network-constrained economic dispatch using real-coded genetic algorithm," IEEE Transactions on Power Systems, vol. 18, no. 1, pp. 198-205, Feb. 2003, doi: 10.1109/TPWRS.2002.807115.

[30] J. Tippayachai, W. Ongsakul, and I. Ngamroo, "Parallel micro genetic algorithm for constrained economic dispatch," IEEE Transactions on Power Systems, vol. 17, no. 3, pp. 790-797, Aug. 2002, doi: 10.1109/TPWRS.2002.800948. 